\title{
Uma sociocosmologia e seus componentes: de um modelo mítico às operações xamânicas Ayoreo
}

\author{
LEIF ERICKSSON NUNES GRÜNEWALD
}

Este artigo trata de um conjunto de narrativas míticas de um povo ameríndio sobre a criação das plantas e dos animais e da destituição de sua pré-condição humana após a cessação dos tempos míticos. Tal ruptura é estudada aqui nas páginas que se seguem à luz da mitologia e da sociocosmologia ayoreo - um povo falante de uma língua Zamuco que habita a região do Chaco Boreal, mas que se dispersou, desde os anos de 1960, até a margem direita do alto rio Paraguay, na altura da cidade brasileira de Porto Murtinho (MS).

Sua pretensão consiste em oferecer ao leitor e a leitora uma descrição desses acontecimentos, juntamente com suas implicações e significações na constituição de mundos heterogêneos, tal como mobilizados no pensamento das pessoas desse povo sobre a socialidade humana e o feitio do mundo que habitam. E ao revisar algo que tem sido dito contemporaneamente a respeito da ideia de ação xamânica, este ensaio também busca reunir dados e ressaltar articulações entre um conjunto de narrativas míticas e as agências xamânicas, a fim lançar luz sobre operações de distribuição e de categorização de diferentes sujeitos ex-humanos em coletivos ontologicamente distintos, mas mutuamente implicados.

Creio, porém, que para o leitor e a leitora familiarizado com o trabalho de Lévi-Strauss - que por meio de diferentes trilhas de geração de sentido interligou diferentes porções semânticas de uma 'floresta' de narrativas míticas provenientes de inúmeros povos de norte ao sul da américa indígena essas formulações não deverão soar como nenhuma novidade.

Afinal, não raramente encontra-se ao longo daquelas páginas, por exemplo, um grupo de narrativas sobre jaguares donos-de-fogo, do qual foram despossuídos pelos humanos; sobre desaninhadores-de-pássaros que, acompanhados do colibri, visitam a morada aquática das almas; tatus executores de vingança; sobre a inimizade do jaguar e do tamanduá e da disputa entre eles em torneios de excrementos e de malabarismos com os olhos fora das órbitas; sobre tartarugas que servem eventualmente de montaria para a lua; sobre anões sem ânus; sobre coiotes sem pênis e responsáveis pelo mau-cheiro do 
sexo feminino; sobre cobras arco-íris que revelam-se simultaneamente a origem do veneno de pesca e das epidemias, e quando não sobre maridos-estrela e mulheres de vários 'tipos': cervo-da-cauda-branca, formiga, tronco, rã ou grampo.

À primeira vista, cada personagem de uma narrativa mítica aparenta ser mais ou menos enigmático $^{1}$ tanto pelo que simboliza quanto pela natureza de suas ações. Contudo, com o virar das páginas, essas figuras cujas tramas compõem diversas sequências articulam-se a uma multiplicidade de esquemas naturais, cosmológicos, sociológicos, estéticos, etc. Estas sequências reconstituem àquele que com elas se depara os traços do desenho de um dispositivo mitológico de pensamento que não estabelece nenhuma relação de transcendência com o próprio acontecimento, quase sempre reputado ter ocorrido no tempo em que inexistia a diferença entre humanos e animais.

E assim sendo, a sensação que se tem a medida em que se encerra a leitura de um dos volumes da tetralogia (ou ainda da trilogia que compões as chamadas petites mythologiques) e se inicia a leitura de outro é que nos encontramos diante de enorme léxico. Um em que cada uma dessas figuras míticas é um termo cujo estatuto é menos o de um objeto que o de um instrumento de significação. Isto é: termos que, num tipo de mundo em que diferentes camadas de humanidade ainda não se encontravam separados, se ocupam menos de atribuir um sentido externo a eles, que de significar a si próprios segundo influências externas e uma razão lógica que desenvolve um jogo de mediações e substituições perfeitamente coerente, e de se exprimir um através do outro. Afinal, como o próprio Lévi-Strauss destacou em O Cru e o Cozido: "seu significado é, antes de mais nada, de posição". (Lévi-Strauss 2004: 79 , grifos originais)

Da parte dos Ayoreo, tais narrativas míticas e os personagens que as povoam, nomeados de Jnanibajade (masc.) e de Chequebajedie (fem.), aludem a um tempo singular nomeado de quicuijáide e de umpemejá. Tempo que segundo as pessoas desse povo passava-se em outro mundo (Ayoreo: erami), no qual todos os animais eram humanos, assim como algumas plantas e insetos; os astros; as estrelas; o sol e a lua, que se diz ter sido findado devido a um primeiro incêndio e um primeiro dilúvio que transformou a topografia do mundo ao inscrever nele um conjunto de distinções.

De uma ausência momentânea de terra e da proliferação de sapos (transformação primária de todos os animais ex-humanos no período pós-dilúvio). Da humanidade indistinta a criação de sete clãs patrilineares ${ }^{2}$, que repartiram assimetricamente tudo que passou a existir no novo mundo ayoreo. Assim contam um pouco as pessoas desse povo, como se nos oferecessem uma pequena amostra de um tipo de bestiário muito mais amplo. Nesse novo mundo, o velho Nirimo se transformou em Caragade, o planeta Vênus. Junto com ele, seis belas moças se transformaram nas Iruinguijane, nas Plêiades, depois de terem decidido visitar o céu e não mais retornar ao domínio terrestre. Depois desse momento, as moças-Iruinguijane, juntamente com os cachorros, passaram a pertencer ao clã Chiquenói, "por tê-los encontrado primeiro".

\footnotetext{
1 E por que não dizer que são até mesmo um pouco cômicos, como, por exemplo, no caso de um mito Munduruku (M389) sobre a origem dos sapos, ou de outro Taulipang (M524) sobre a origem da digestão.

2 São os sete clãs ayoreo: Picanerai, Chiquenói, Dosape, Cutamorajai, Jnurumini, Posarajai, Etacori.
} 
Pelo mesmo motivo, o clã Picanerai teria transformado Caragade em posse sua, enquanto o clã Etacori se apropriaria do dia (Ayoreo: diri). Ao clã Dosape teriam cabido os animais da floresta, em especial os tamanduás. Ao clã Jnurumini, teria cabido a morte (Ayoreo: pitoringai) e seus desdobramentos (cf. Fischermann 2001), assim como teria restado ao clã Posorajai se transformar no dono das vacas e das lagoas, e ao clã Cutamorajai no dono do fogo e dos troncos de quebracho (Schinopsis balansae).

Há certamente mais. Se, por um lado, bastará que chamemos a atenção para um aspecto da relação entre um modelo de organização social e uma descrição do povoamento do mundo habitado agora pelos humanos-de-verdade, Ayoréode (o que não parece ser menos importante de afirmar no contexto dessa discussão), por outro convém ainda estudar de modo mais detalhado outras transformações estimuladas pelo fim dos tempos míticos que levaram a resultados parecidos. Pois vejamos mais de perto.

\section{(De)viradas animais}

O início do tempo de Asojna, a Engole-Vento, simboliza um tipo de 'fechamento 3 do mundo", que exige dos homens que ainda não são chefes de algum grupo doméstico (Ayoreo: iriatade) que se afastem da aldeia, e convoca os que já o são a acenderem pequenos fogos e ornarem-se com a cinza fria tanto por ocasião do amanhecer quanto do entardecer do dia.

Ornar-se assim é condição para que se possa sair (sempre em jejum) durante o tempo de Engole-Vento em busca de mel ou de alguma presa de caça. É preciso ainda que, dado o retorno do caçador à aldeia silenciada pelo temor das retaliações de Asojna, que se agarre uma borduna mantida durante todo esse tempo sob a terra, que se golpeie levemente o recém-chegado, e que se coloque em sua boca um pedaço de tronco de caraguatá.

Tal ato é pré-condição para que o homem ou a mulher de retorno possam até mesmo beber água. Caída a noite, resta àqueles que permaneceram na aldeia amarrar as bordunas em forma de cruz e gritar a pleno pulmões para Asojna: - "nós já vamos dormir!”. Anúncio que deve cessar, então, os sons produzidos por quase todos da aldeia, exceto um. Aquele que deveria permanecer acordado por toda a noite, munido de seu maracá, zelando pela proteção dos outros contra os 'castigos' (é a palavra empregada pelos Ayoreo) da Engole-Vento. É, em o tempo de Asojna, como disse Peebi certa vez na aldeia Tiogai, localizada no alto Paraguay, "o tempo em que tudo fica morto".

Conta-se ademais que durante os tempos míticos, Asojna teria sido uma chefe velha e feia, e uma feiticeira (Ayoreo: payé) absolutamente poderosa, dona do fogo doméstico dotada tanto de grande capacidade de xamanizar, de roubar as sementes das roças, e de promover grandes incêndios a fim de tentar exterminar definitivamente os Ayoreo. Além disso, Asojna tentava constantemente seduzir e recrutar um grande número de auxiliares (Ayoreo: irigode) para servir a si própria e seus anseios, a seu

3 A ideia de "fechamento" empregada para caracterizar a estação seca ecoa diretamente na caracterização que Sebag nos oferece sobre a estação chuvosa, sequere, a qual descreve como tempo de "abertura do mundo". (Sebag 1977: 71) 
marido potajnai $i^{4}$ (outra espécie de Caprimulgo), seu irmão ${ }^{5}$ Jnanucutói, o condor, e seu filho Poji, o iguana.

Um dia, sedentos de vingança, os índios se aliaram a Poji e a Jnanucutói a fim de assassinar Asojna, que se encontravam assaltados pelo ciúme da Engole-Vento. E ela, convencida de sua desgraça, tratou de entregar o fogo que possuía à uma ave aquática a fim de que esta vingasse sua morte quase-inevitável promovendo um grande incêndio ${ }^{6}$ na floresta, e evadir o espaço da aldeia juntamente com seu Potajnai.

Após a extinção do incêndio universal que queimou, por exemplo, o estômago do cachorro-tamocói (por isso os cães teriam contemporaneamente, segundo os Ayoreo, o abdômen delgado), o pescoço dos urubus (por esse motivo estes teriam o pescoço 'careca') e fez proliferar entre os Ayoreo um conjunto de doenças, especialmente a febre, Asojna, incapaz de resignar-se, ainda promoveu xamanisticamente um grande dilúvio, contido pelo esforço coletivo de xamãs ayoreo somado a ação xamânica de Kiekie, o gavião-carcará, e Chunguperedatei, o jaburu (tornados inclusive capazes de curar as enfermidades provocadas pelo incêndio de Asojna).

Os Ayoreo sobreviventes, por vingança, esconderam Potajnai embaixo de um cobertor e disseram à Asojna que ele o havia abandonado. A Engole-Vento escutou sem dizer uma palavra e conta-se que o pesar a levou a querer abandonar o espaço da aldeia, deixando um recado para todos: - "vocês verão! Todos os anos farei chover muito!".

Mas durante sua fuga, os habitantes da aldeia se lançaram sobre ela (especialmente o arbusto dajnuri, um dos que tinham mais raiva de Asojna) para capturá-la, e trataram de acender uma grande fogueira para queimá-la viva. Após o assassinato de Asojna, o lagartixa Imochai recolheu seus restos queimados e os carregou até a aldeia das lagartixas, onde a ressuscitou xamanicamente com a ajuda de cantos e batidas de um maracá. No momento seguinte, já ressuscitada em uma aldeia-imochai ${ }^{7}$, Asojna optou por alterar sua forma e atualizar-se num modo Engole-Vento e por isolar-se na floresta, não sem antes impor aos Ayoreo vivos pós-incêndio e pós-dilúvio uma série de proibições que passaram a pautar seu modo de existência.

Pois bem. Mas a história de Asojna menciona o iguana Poji como um tipo de filho-traidor, com seus aliados (o tio-condor e os Ayoreo, que permaneceram atualizados num modo humano mesmo após as tentativas de Asojna de dizimá-los). Detenhamo-nos por um momento em alguns aspectos do que os índios contam a respeito da história de Poji.

Desse universo narrativo, atentemos especialmente para a história de que o iguana filho de Asojna possuía, tal como a mãe, grandes dons xamânicos e de futuração. Em dias de caçada, previa certeiramente: - "meu pai Potajnai e os outros Ayoreo [míticos] que foram com ele caçar trarão muitos

\footnotetext{
4 Reputado ser, segundo Sebag (1977), um homem belo e simpático e “o melhor cantor entre os Ayoréode.

5 Sobre a família de Asojna, ver os trabalhos de Kelm (1971), Sebag (1977) e Fischermann (2001).

6 Segundo uma observação de Fischermann (2001), durante o evento do incêndio mítico o fogo de Asojna teria se alojado no interior do tronco das árvores, o que teria permitido que os Ayoreo pudessem produzir fogo, após o fim dos tempos míticos, por meio da fricção de bastões de madeira.

7 Esse ponto sobre uma aldeia-imochai distinta da aldeia Ayoreode ainda permanece para mim um pouco ambíguo. Sobretudo por um tipo de sensação de achatamento da diferença entre um modo mítico de organização da existência humana e um modo não-mítico de humanidade.
} 
tamanduás! Cada um caçará um!! Vocês já verão!”. E logo podia-se ver o grupo de homens, liderado por Potajnai, retornar à aldeia com o grande butim da caçada. Durante a organização de uma expedição de coleta de mel, atestava: - "Papai e os outros retornarão com muitas cabaças cheias de mel! Eu já os vejo! Eles já chegarão!”.

Admirado por todos, $P o j i^{8}$ não viveu muito devido a um conjunto de enfermidades que começou a atingi-lo e contagiar os Ayoreo. Já tendo encontrado a morte de Poji, os iguanas juntamente com o coelho Guiorama se reuniram a fim de recompor uma imagem do corpo do filho-iguana de Asojna. Cada um deles recolheu um pouco do pó em que o cadáver de Poji havia se transformado e sob a orientação de Guiorama passaram a soprá-lo a fim de recriar xamanisticamente um corpo para o iguana.

“Sopre! Sopre! Sopre! Ele já reviverá!", dizia-lhes o coelho. Desobedecendo Guiorama, os iguanas, ao pressentirem a ressuscitação de Poji, pararam de soprar e expulsaram o coelho, sem que houvesse tempo dele recolher todos os objetos que eram de sua posse. Apesar de sua expulsão, e devido a um sopro desastrado, Guiorama espalhou todas as cinzas de Poji sobre si, ganhando a cor branco-acinzentada que lhe é peculiar.

Nesse mito, curiosamente, tudo parece acontecer ao contrário do que vimos na história de Asojna: o iguana é quase-ressuscitado a partir de suas cinzas e é um repositório de enfermidades. Se no segundo mito narra-se um tipo de reavivamento "metonímico" (a partir das cinzas do iguana), no primeiro trata-se de uma morte "hiperbólica" (pelos integrantes do grupo doméstico e pelos integrantes da aldeia). Se, portanto, na história de Asojna a xamã Engole-Vento é morta e queimada por um coletivo (principiado por uma traição de parte de seu grupo doméstico) e ressuscitada por um esforço individual, o contrário se passa com Poji, ressuscitado por um esforço coletivo e quase-traído por um desajeito individual.

Tudo isso é verdadeiro, mas, por outro lado, não podemos desconsiderar que há um ponto que conecta o mito da engole-vento ao mito do iguana. A história de Asojna e a gesta de Poji assemelham-se igualmente no sentido de que o engole-vento e o iguana desempenham neles o papel de xamã. Além disso, tampouco podemos ignorar que entre os Ayoreo, a história da engole-vento liga-se a outra sobre um embate de poderes xamânicos, que figuram como igualmente atribuídos ao jaburu Chunguperedatei.

Comecemos então por sua descrição. Os Ayoreo contam que antes de passar a existir em modo não-mítico, o jaburu figurava como o grande chefe daqueles que viriam a ser transformados após o fim dos tempos míticos em aves aquáticas. Os Ayoreo dizem também que o jaburu era capaz de desempenhar tanto o papel de chefe quanto o de grande matador, dono do ferro ${ }^{9}$ e marido de Quenegate, uma mulher-aranha reconhecida pelos Ayoreo como uma tecelã habilidosa e famosa pelas redes e cobertores de caraguatá (Bromelia pinguin).

8 Pode-se depreender a partir da conciliação entre o mito e alguns filamentos da etnografia ayoreo que as enfermidades que atingem Poji aparentam operar por semelhanças, isto é, pela criação em Outrem de imagens da própria doença. Nesse sentido, pode-se dizer que Poji também é, de certa forma, a epítome de um grande número de enfermidades que atingem contemporaneamente os Ayoreo.

9 E se há quem atribua a origem do ferro que Chunguperedatei passou a possuir exclusivamente à solitária Yiguedojna (a 'estrela' em que Bremen (1991) reconheceu Vênus), saqueada certa vez por Chunguperedatei, que lhe roubou seus melhores facões, por Gatodejájnai, o tatu-canastra e grande ladrão de machados; e Asai, o pica-pau (Celeus lugubris) que, mais modesto, só levou consigo um prego. 
Porém, não tardou para que a vida do jaburu se complicar: "Por que Chunguperedatei tem facões e nós não temos? Não é justo. Vamos matá-lo!”, perguntava o tatu-canastra Gatodejájnai, portando a voz de todos os sujeitos habitantes do domínio subterrestre (Ayoreo: jnaropié). Um dia, o tatu-canastra Gatodejájnai aproveitou-se de um ataque surpresa à aldeia do tatu-peba judui (promovido por Chajñua e por Ajnirai, tornados os responsáveis por atar e estrangular Chunguperedatei) para matar o jaburu e tomar seus facões, suas colchas, seu sangue (do qual o cacto Darujna se apropriou) e suas plumas (que passaram a ser de posse dos roçados, siquere).

Essa mudança na apropriação do ferro figura, na história do Jaburu, acompanhada de outra, que se encontra no fato da constituição de um tipo de ética da vingança ${ }^{10}$ a partir da morte de Chunguperedatei e da repartição involuntária dos bens que possuía. Isso porque sucedeu esse evento o assassinato do tatu-canastra Gatodejájnai pelo tatu-peba Judui (o que teria reforçado a querela existente entre os dois até os dias de hoje e estimulado a transformação voluntária de várias pessoas humanas em animais) e o saque dos antigos bens de Chunguperedatei, dos quais o tatu-canastra havia se apropriado primeiramente.

Assim, Judui e o tatu Jochacai começaram sozinhos, viajando de aldeia abandonada em aldeia abandonada, uma busca pela sepultura do jaburu, onde julgavam poder reconquistar o resto do ferro que Chunguperedatei possuía. Espalhado então o rumor da busca pelos restos do Jaburu, um numeroso grupo de animais, ex-humanos e pertencentes ao clã Chiquenói, trataria de se juntar a Judui e a Jochacai, incumbidos da tarefa de cavar buracos e espantar os morcegos que deles saíam. A expedição do grupo tem sucesso e assim que se encontrou o lugar em que o Chunguperedatei havia sido enterrado, o tatu-peba reuniu todo o ferro e reclamou para si próprio sua posse exclusiva. E à vista disso, os animais decidiram acabar com ele e repartir novamente o ferro entre eles.

O principal protagonista aqui pode ser o jaburu dono do ferro, o tatu-canastra traidor, ou o tatu-peba egoísta. Seja quem for, a história de Chunguperedatei nos traz uma imagem importante: as investidas de um tatu contra o outro provocou a transformação de outros protagonistas, vinculados a um único e numeroso clã, em animais para escapar dos efeitos dos ataques de Gatodejájnai a Judui. Com efeito, ela implica ainda numa espécie de relação de equivalência entre uma transformação ontológica voluntária e uma cromatização da propriedade de um bem cultural, do qual no início o jaburu era o único dono, como efeito de uma sucessão de assassinatos. Tratava -se, então, da triplicação de um acontecimento e de uma espécie de 'trans-apropriação' de objetos de ferro para superar um desequilíbrio que se desenrola em planos e em momentos distintos.

Cumpre relembrar também que os Ayoreo reconhecem igualmente dois outros movimentos simétricos e inversos de transformação ontológica motivada pela ação destrutiva de Outrem que criaram oposições entre humanos e ex-humanos que passaram a figurar como animais. Um na história de Asojna, em que os restos queimados da Engole-vento são reunidos e reconstituídos, via ação xamânica, num modo humano, que decide então transformar voluntariamente sua própria condição numa não-

10 Assim sendo, segundo Bremen (1991), faz-nos atentar o que se justificaria através da história de Chunguperedatei é a própria necessidade da guerra como único meio de se obter os bens dos quais o Jaburu se tornou dono (e que são associados contemporaneamente aos Brancos, cojñone). Inclusive, associar-se-ia os estes objetos feitos de ferro remanescentes da Guerra do Chaco (1932-1935) à Yiguedojna e os terrenos em que podem ser eventualmente encontrados às áreas por onde teria passado Chunguperedatei. 
-humana e alhear-se da companhia das pessoas de um povo não-humano na floresta. Outro na de Poji, em que o iguana-xamã enfermo é quase-ressuscitado num modo não-humano a partir de suas partes queimadas mediante uma tentativa xamânica desastrada que desintegrou uma unidade que tentava se recompor.

Avançando mais um passo, agora à luz dessas considerações, cumpre agora completar tratando de um grupo de narrativas sobre atualizações e reconfigurações de sujeitos humanos e modos não-humanos de existência e reter delas alguns aspectos que interessam diretamente a nossa análise aqui.

Primeiramente, o jaguar, Caratai. Antigamente, vivia entre os Ayoreo um caçador tão desastrado e barulhento que nunca conseguiu caçar um animal. Seus pés faziam tanto barulho na floresta que podia ser ouvido ao longe por todos que poderiam eventualmente se transformar em presas suas. Todos os tipos de caça se espantavam do caminho trilhado por ele, pois suas mãos eram ruidosas demais. Um dia, o caçador barulhento cansado de sua vida faminta rezou para Deus (Ayoreo: Dupade) para tornar-se um caçador menos desastrado e conseguir se alimentar. Dupade transformou, portanto, e num primeiro momento, suas mãos em mãos-de-jaguar, donde teria principiado a transformação integral do caçador ex-desastrado num jaguar ex-humano, completada por Deus a fim de que o jaguar se tornasse seu próprio cão-de-caça e assim pudesse caçar.

E a novidade sobre a transformação do caçador no 'cachorro-de-Dupade' logo se espalhou pela aldeia. Um dia, apareceu-lhe um homem e lhe pediu: "me empreste seu cachorro porque não aguento mais não caçar nada!". O dono do jaguar concordou e o homem imediatamente levou consigo o 'cachorro-de Dupade. Ao ir embora, porém, Deus recordou-se que havia esquecido de dizer ao homem que não podia se apropriar do primeiro animal que o jaguar caçasse, pois este devia ser reservado para seu próprio repasto. $\mathrm{O}$ homem inadvertido, animado com a previsão de um grande butim da caçada, logo tratou de recolher para si o primeiro animal caçado pelo Caratai. Enfurecido, o jaguar não hesitou, então, em devorar prontamente o caçador. De volta a aldeia sozinho, Dupade percebeu então que a cara do jaguar estava completamente ensanguentada, a partir do que constataria que algo tinha realmente acontecido com o caçador desavisado.

Há, ainda, mais relatos do mesmo gênero. Nesse mesmo tempo, havia na aldeia em que o jaguar vivia a moça mais bonita da região, admirada por todos por sua beleza e por sua habilidade de tecelã reconhecida em sua capacidade de produzir grandes bolsas e cobertores de caraguatá - que se transformou voluntariamente no chupim (Molothus bonariensis). Outra habitante da aldeia, a formiga Najom era reputada ser uma mulher ayoreo, uma trabalhadora incansável que percorria diariamente o mesmo longo caminho dia após dia para cuidar de suas roças, e parente de um homem ayoreo famoso por seu corpo gordo e seu enorme apetite, famoso por comer glutonamente o que quer que lhe oferecessem, que se transformou voluntariamente no porco-do-mato Ijancói.

Além disso, também havia ali três homens ayoreo de quem muito se ouvia falar. Um por sua grande agilidade e rapidez, que lhe permitiam cruzar velozmente de uma localidade a outra do Chaco sem que nem mesmo um espinho lhe machucasse os pés. Outro, cuja fama era a de conseguir curar espontaneamente qualquer ferimento em seu corpo. E um terceiro, que era tão grande e tão forte que 
quase não sentia dor e era capaz de carregar grandes pesos. E que se tornaram, respectivamente, o tatu-galinha, Ajaramei; o samu'u (Ceiba chodatii), Curucuichai; e o cavalo, Mborevi.

Mas ainda a respeito dessas transformações ontológicas voluntárias, uma história dos Ayoreo sobre um homem chamado Tinaina contém uma indicação que não é menos interessante. Conta-se que por razão direta de sua maldade excessiva, esse homem foi exilado do espaço da aldeia dos Ayoreo humanos, para que por ali morresse. Sozinho no mundo e inconformado com seu próprio destino, Tinaina curou xamanísticamente sua própria maldade e retornou a aldeia. "Mas por que você está aqui se deveria estar morto?" - perguntaram os habitantes da aldeia. Para o que Tinaina respondera: "Estive fazendo orações ${ }^{11}$ e me recuperei. Venci minha própria maldade. Por isso gostaria de voltar a viver aqui.", com o que todos finalmente concordaram.

De volta ao convívio dos homens, Tinaina passou a dar lições de xamanismo àqueles que acreditavam estar doentes. Principalmente, o jaguar, que se queixava constantemente com ele: "não tenho apetite, nem tenho vontade de andar! O que devo fazer? Como você consegue comer? Vomito sempre que como da carne de outros animais". Diante do que Tinaima lhe aconselhava: "sempre faço orações e me tranquilizo. Assim sinto vontade de andar. Você não consegue comer porque seu corpo está cheio de ar quente. Sopre-o e assim você, como eu, conseguirá comer em excesso tudo o que quiser!”.

Seguindo seu conselho, o jaguar, já vazio das doenças e do ar quente que lhe impedia de comer, começou uma caçada violenta contra uma parentela reduzida que se resumia a um chefe, sua irmã e um grupo de homens. Estes, para fugir do ataque do jaguar, transformam-se em mosquitos (o chefe num mosquito maior e sua irmã e os outros que restaram em mosquitos menores). Alimentado, mas sedento, o jaguar decidiu procurar um lugar onde pudesse beber água e aplacar sua sede. Diante de uma grande lagoa, e ao beber o primeiro gole, o jaguar constatou que sua água era completamente salgada. O jaguar ficou sem saída: quanto mais bebia, mais sede sentia, e como não podia saciar efetivamente sua sede morreu. Então Tinaina, diante da transformação voluntária de uma parentela humana em mosquitos para fugir do ataque violento do jaguar morto de sede, optou por transformar-se no gavião-carcará, Kiekie ${ }^{12}$.

Haveria, porém, algum fio condutor que interligaria essas narrativas umas às outras?

À primeira vista, essa prospecção permite-nos notar que estamos diante de uma afinidade entre a voluntariedade da transformação na condição ontológica de um grupo de sujeitos ex-humanos e um conjunto de comportamentos ou de características tidos aqui como "hiperbólicos". Uma moça excessivamente bonita se transformava no chupim; um homem excessivamente desastrado e faminto transformava-se no jaguar; um homem gordo e grande glutão convertia-se voluntariamente no porco-do-mato, da mesma maneira que um homem excessivamente ágil se tornava o tatu e outro distintamente forte transformava-se no cavalo.

O que não parece ocorrer no caso dessas histórias por mero acaso. Sobretudo porque, por um lado, tal característica nos faz recordar do que Lévi-Strauss (2004: 384) escreveu sobre o que chamou

11 É através do emprego da expressão "fazer uma oração" que os Ayoreo contemporâneos definem aquilo que caracteriza o modo atual de ação xamânica.

12 Que teria ainda, como vimos acima, papel fundamental no combate ao incêndio promovido por Asojna. 
de uma "predileção" dos mitos pelas hipérboles. Recordemos que para o autor, seu emprego seria, para além de um mero recurso retórico, a "sombra visível" de uma estrutura lógica, que ao inscrever um modelo das relações humanas num contexto cosmológico mais amplo (que se espalha para muito além delas) e quando tomado em sua totalidade, revela-se ser um sistema isomorfo à dimensão cósmica que pode, à sua maneira, tanto incluí-la quanto imitá-la.

Tudo parece se passar então como se o caráter desses personagens, somado às outras descrições sobre atualizações de centros de agência em modo animal e não-mítico, iluminasse um aspecto geral dessas transformações em animal no pensamento ayoreo. Um que remete ao cruzamento de um limiar, que possibilita que essas figuras se estendam sobre um novo continuum de intensidades, no qual as formas que assumiam anteriormente são desfeitas juntamente com todas as significações, significantes e significados prévios, atingindo, assim, um novo nível da socialidade humana: uma zona de novas intensidades cujos conteúdos encontram-se desatados das formas e expressões que as formalizavam num fundo comum e mítico de humanidade compartilhado por todos.

Assim, podemos perceber que não se trata aqui da reprodução de figuras humanas numa série (e sob uma forma) não-humana. A humanidade mítica de um não é aqui um modelo evidente para a ex-humanidade não-mítica do outro. Ao contrário, trata-se da ideia muito distinta que esses processos de atualização de figuras míticas num modo não-mítico e não-humano asseguram o abalo de uma estrutura ontológica anterior (que tornavam certo o desempenho estruturado da capacidade de produzir representações sobre um mundo), bem como a modificação do modo de existência de um sujeito, fazendo assim com que a animalidade opere aqui como a composição de uma estrutura e reestruturação de uma maneira de existir.

A questão que ainda nos cabe colocar é, portanto: tendo em vista essa ideia de que a transformação no animal opera como um mecanismo de criação de um modo de existência ontologicamente distinto, e dado que tanto um gênero de existência quanto o outro figuram no pensamento Ayoreo como plenamente reais, que é que surgiria então da passagem de um modo ao outro? Ou ainda, e colocando a mesma questão em outros termos, o que é que se instaura nesse (e a partir desse) intervalo constituído entre dois modos de existência?

Minha hipótese é, em suma, a de que no pensamento das pessoas desse povo encontram-se situado no intervalo entre um plano mítico e outro constituído a partir da cessão dos tempos míticos, efeitos do encontro de perspectivas distintas relacionados ao xamanismo, tomado aqui como um modo de ação vinculado a comparação entre dois modos de existência temporalmente e ontologicamente divergentes. Da ação xamânica ayoreo se pode sugerir ainda que ele se alimenta da substituição temporária de uma intensidade humana por um estatuto existencial absolutamente não-humano, construindo um circuito curativo que corta transversalmente diferentes modos de existência.

\section{A palavra do xamã: modos de relacionar relações}

Tipicamente na paisagem etnográfica das terras baixas da América do Sul, os modelos ameríndios de ação xamânica são quase sempre ditos consistir, segundo Sztutman (2005: 361), num conjunto 
de capacidades agentivas que apesar de encontrarem-se disponível para todos, são controláveis apenas por alguns: os xamãs.

Em linhas gerais, pode-se afirmar, conforme discutiu Sztutman (idem: 379), que tais modelos xamânicos de relação com a alteridade consistem num modo de mediação entre sujeitos humanos e não-humanos que tanto supõe a existência de uma qualidade distribuída no cosmos ameríndio (e passível, portanto, de ser apropriada na forma de um acúmulo de relações com diferentes sujeitos), quanto uma tentativa de reestabelecer uma comunicação perdida e necessária, cuja imagem se encontraria retratada nos mitos, da qual depende a apropriação de capacidade agentiva para a produção de pessoas e de coletivos.

E tal é o caso que os xamãs ameríndios emergiriam, conforme aponta esse autor (ibidem), como:

"Mediadores por excelência, como os agentes de uma cosmopolítica e, sobretudo, como aqueles que dispõem de certas capacidades de ação e transformação, potencializadas pelas relações que eles mantêm com os agentes — não-humanos, invisíveis — do cosmos".

Assim e em suma, o xamã ameríndio consiste na figura dotada das tarefas de zelar pelo funcionamento harmônico do cosmos através do emprego de sua capacidade de transitar por diferentes andares do mundo e de engajar-se em relações com as formas de alteridade características de cada um.

Nesse sentido, parece difícil deixar de pontuar ainda que o xamanismo, conforme Sztuman (2006) argumentou, encontra-se engajado no desenho de uma rede de relações de afinidade potencial e de inimizades que incluem tanto humanos quanto não-humanos. Logo, é igualmente possível afirmar acerca do xamanismo que ele pode ser pensado como um movimento que conduz sempre à exterioridade, fazendo da ação xamânica um tipo de atividade de objetivação das relações acumuladas pelo xamã a partir desse movimento de exteriorização. E justamente nesse processo de personificação da exterioridade reside a base para a constituição, conforme afirmou Sztutman (idem), de interioridades e de coletivos. Quanto maior a agência obtida no fora do socius, maior a fonte para a composição de certos tipos de sujeitos.

No que se refere ao quadro específico do xamanismo chaquenho, não imagino que se possa começar de outra parte que não do trabalho de Alfred Métraux. Ainda em 1946, ao publicar "Ethnography of the Chaco", o autor destaca que a possibilidade de xamanizar efetua-se, entre diferentes povos chaquenhos, a partir da associação do xamã com um espírito auxiliar, responsável por auxiliar o xamã em tarefas difíceis e lhe revelar segredos e acontecimentos futuros. Além disso, segundo constata o mesmo autor, se a possibilidade de ação do xamã chaquenho é dependente de sua associação com espíritos auxiliadores, sua alma é que se encontra verdadeiramente em cargo de, fora do corpo, visitar o sol e "país dos espíritos", em busca de relações para cura de enfermidades.

Métraux aponta ainda que a principal função atribuída aos xamãs é curar enfermidades através da extrusão de corpos estranhos (atribuídos muitas vezes como causas das enfermidades). Nesses casos, através do emprego de um método identificado como difundido entre todos os povos chaquenhos ba- 
seado em recitações monotônicas de uma mesma fórmula, em sopros e sugações do princípio material do interior do corpo da pessoa enferma.

Ainda na mesma análise, o autor argumenta que outra das funções principais atribuídas aos xamãs chaquenhos é a de proteger as pessoas de uma determinada comunidade contra a 'maldade', expressa na forma da agência agressiva de espíritos não-humanos. Curiosamente, a observação de 1946 aparenta coadunar-se com outra do mesmo autor, publicada postumamente apenas em 1967. Nessa intervenção, dedicada especificamente a comparação de dados históricos e monográficos sobre o xamanismo de diferentes coletivos dessa região e ao estabelecimento inferencial de conexões lógicas entre eles com o intuito de descortinar o que chama de “função do xamã”, Métraux enquadra dentre as incumbências do xamã chaquenho a cura das enfermidades e o manejo das relações com o sobrenatural. Sua dupla atribuição é o que lhe permite ser apreendido como "aquele eleito pelas divindades" e, portanto, o homem mais rico e valorizado de um determinado grupo.

Dentro dessa corrente, Clastres, ao colocar, também em 1967, a questão sobre "de que riem os índios" diante da etnografia Nivaclé ${ }^{13}$, constatou que xamãs são, num determinado grupo, os únicos a possuir poderes sobrenaturais e os únicos aptos a controlar as relações com um mundo perigoso habitado por mortos e espíritos. Assim, se o xamã descrito por Clastres é alguém que "causa a vida” (idem), colocando seu conhecimento de curar enfermidades a serviço de seu grupo, ele é também alguém que pode tirá-la, tornando-se dono da morte pela capacidade de matar que possui. Nesse sentido, o xamã é tido como ser perigoso, inquieto e de quem as pessoas constantemente desconfiam.

A desconfiança não é, porém, empecilho para que diversos grupos do Gran Chaco distingam quem é um bom xamã e quem não é. Segundo Clastres, muitos grupos chaquenhos partilham a convicção de que apenas os bons xamãs são capazes de ascender à morada celeste do Sol. Era essa viagem e as relações estabelecidas com esse centro de agência que atestavam sobre o talento ${ }^{14}$ do xamã e sobre a riqueza de seu conhecimento, dado que ela permitia, em tese, que o xamã indagasse o sol sobre o que quisesse.

É, porém, no livro de Pastor Arenas (1981), que podemos encontrar uma descrição sobre a ação xamânica que se conecta parcialmente com o modelo apresentado por Sebag e com a descrição de Clastres sobre o xamanismo Nivaclé. Segundo Arenas, o xamã chaquenho reconhece, em seus sonhos ou por meio de seus cantos e transes, são capazes de reconhecer os espíritos como pessoas e são, reciprocamente, reconhecidos como humanos por eles. É o que se pode ler na célebre entrevista que esse autor (1981: 29) fez com um xamã nomeado Mita Puku. Segundo ele, as cobras e os jaguares "estudados" pelo xamã através de seus sonhos são vistos como pessoas, comem batata doce. E são eles vistos respectivamente como os donos das cobras e dos jaguares.

13 Falantes de uma língua da família Mataco-Mataguayo habitantes de ambas as margens do rio Pilcomayo.

14 Somado a esse critério, havia outro. Para os Nivaclé, outro critério para se apurar a potência (juntamente com a 'maldade’) dos xamãs era a habilidade de se transformar em jaguares. Se sob esse critério encontrava-se a aproximação de dois mitos das pessoas desse povo, ele também implicava na substituição de uma relação exterior entre jaguares e xamãs por uma relação de identidade, afinal, para Clastres (1967 grifos originais), "de certo ponto de vista, os xamãs são os jaguares". Ambos são "risíveis" dada a possibilidade para o pensamento indígena de realizar a conjunção impossível entre dois mitos. 
Agora, já nos anos 2000, que foram palco dos efeitos produzidos pelos desenvolvimentos subsequentes da teoria etnográfica do perspectivismo ameríndio (Viveiros de Castro 1996, Lima 1996) e pelas reproblematizações a respeito das noções de corpo e de pessoa, o xamanismo chaquenho elaboradas durante os anos de 1980 e 1990, também foi descrito como um modo de ação que permite examinar como a pessoa se constitui a partir de uma continuidade temporal com os outros existentes.

Desses trabalhos, podemos destacar a etnografia de Tola (2004; 2011) com os Toba (Qom), onde ressalta-se que se o corpo é pensado como fronteiras entre pessoas e como espaços de individualidade, o corpo do xamã Toba é poroso, feito de extensões que circulam entre seres humanos e não-humanos. Desse modo, a porosidade do corpo acompanha a existência de sensações divididas que ultrapassam os limites impostos pela pele, e a capacidade curativa ou agressiva do xamã figura como dependente da capacidade de mobilizar relações com agências não-humanas.

E há outra monografia recente digna de nota que nos coloca diante de um desenvolvimento interessante sobre a ação xamânica no Chaco é a tese de Villagra (2010) entre os Angaité, que nos permite avaliar como o xamanismo provê os meios de lidar com as transformações num "mundo vivido" (Gow 2001), ao oferecer uma chave de interpretação em que os Angaité não são vítimas ou observadores passivos circunstâncias histórias. Ali a ação xamânica figura menos como modelo de ação em declínio que como potência de forças latentes e imprevisíveis que podem ser sempre atualizadas pelas pessoas desse povo através da incorporação de novas técnicas e de novos espíritos auxiliares. Nesse sentido, as técnicas dos xamãs Angaité são menos prescritivas que experimentais e inovativas, e a existência atual dos xamãs atrela-se a contingentes não só históricos, mas contextuais e agenciais.

Pois bem. Que é, em todo caso, o xamanismo tal como mobilizado pelos Ayoreo?

A resposta que a etnografia desse povo nos dá é uma que parece ser quase passível de ser posta nesses termos: - 'depende do tempo e da localidade'! Isso porque voltando ao texto célebre de Sebag (1965: 94) sobre o xamanismo desse povo no alto Paraguay e na Bolívia, é possível observar que descreveu-se ali a ação xamâmica como efetuada a partir de sopros e sugações (como no modelo descrito por Métraux), mas também por meio do emprego de uma classe de fórmulas sagradas denominadas ujnarone, que dão força vital a um ser, e que se confundem, segundo esse autor, com a própria respiração de um sujeito, uma vez que, conforme a descrição de Sebag, as palavras que compõem cada um dos recitos ujnarone correspondem apenas ao "suporte de um poder que confunde-se com o sopro de cada sujeito". Poder invisível que, levado ao encontro do interior do corpo da pessoa enferma, torna-se capaz de destruir qualquer objeto potencialmente patogênico.

Já segundo a descrição de Otaegui (2014: 61-62) sobre os Ayoreo do Chaco Boreal, é possível observar também que o emprego das ujnarone, conjuntamente com o de fórmulas nomeadas de sarode (ambas dotados de uma estrutura fixa e de conteúdo extraído de narrativas míticas e herdadas dos seres Jnanibajade e Chequebajedie) consistem numa intervenção individual que efetua-se pela enunciação ${ }^{15}$

15 No que concerne ainda a maneira de enuncia-las, os Ayoreo não considerariam os sarode como um canto xamânico, mas como um tipo de fórmula cuja enunciação (que não carece de ser acrescida da narração do mito) apresenta uma estruturação sonora e um ritmo. Os sarode teriam ainda, segundo Otaegui, um traço específico que os distingue, por exemplo, dos ujnarone: a presença de onomatopeias da dor, ou da doença, ou, em alguns casos específicos, de um corpo em boa saúde. 
da fórmula xamânica somada a sopros (Ayoreo: chubuchu) sobre a parte do corpo afetada, para só então soprá-la na direção contrária.

Adicionalmente, segundo a descrição de Fischermann (2001) realizada a partir de seu extenso trabalho com um grupo Ayoreo na Bolívia durante os anos de 1980, a capacidade de xamanizar figura como estreitamente dependente da ativação da capacidade xamânica puopié16 promovida pela ingestão tanto de uma larga quantidade da bebida fria preparada com as folhas verdes de tabaco (Ayoreo: sidi), quanto da fumaça quente do tabaco fumado no cachimbo borijnai.

Uma vez ativada, a capacidade puopié propicia que o duplo anímico da pessoa (Ayoreo: oregaté) de entreter-se em relações com formas não-humanas de alteridade igualmente dotadas de capacidade xamânica, como, por exemplo, o jaguar (tido como uma espécie de xamã prototípico), o gavião-carcará ou o urubu. Assim, o autor destaca que a capacidade xamânica puopié configura a "abertura de um novo mundo" (idem: 235-236). Abertura expressa, por sinal, na conversão da perspectiva do próprio xamã (Ayoreo: daijnai). Ao ativar o puopié mediante a absorção da fumaça de tabaco, o xamã habilita-se a ouvir e a enxergar tanto os duplos anímicos (Ayoreo: oregaté) de seres míticos quanto das próprias enfermidades, podendo, nesse caso, ouvir seus cantos de guerra contra as pessoas humanas e prevenir contra suas investidas, ou mesmo dissuadi-las de promover ataques contra o duplo anímico das pessoas humanas.

Esse autor (idem: 234) chama a atenção ainda para o fato de que as formas de alteridade com quem o duplo do xamã engaja-se em relações são responsáveis por indicar concretamente como curar alguém da enfermidade que lhe acomete. Contudo, não há nenhuma obrigatoriedade no auxílio que uma ou outra forma de alteridade pode prestar a um xamã. Assim, para Fischermann, na prática, a condição de xamã aparenta estar vinculada a condição de mobilizar relações de auxilio junto aos seres Jnanibajade e Chequebajedie. Ali e em suma, só pode ser xamã quem é capaz de mobilizar relações ${ }^{17}$ com centros de agência não-humanos.

Da interação com não-humanos à conversão de perspectiva, o autor (idem: 236) chama a atenção ainda para a possibilidade conferida àqueles que podem xamanizar de transformar o duplo anímico dessas formas de alteridade em veículo para se transportarem para outras localidades. Assim, o duplo dos morcegos e do pequeno tornado úyujna são tidos pelos xamãs Ayoreo como meios de transporte privilegiados tanto para acessarem ou localidades distantes (e até mesmo o patamar celeste do cosmos), quanto para levarem o duplo da pessoa enferma ao encontro das estrelas Nujinguijnaminie, a fim de facilitar ali seu processo de recuperação. Por outro lado, o duplo anímico do iguana Poji é considerado o melhor transporte para o domínio subterrestre jnaropié. Seja qual for o caso, esse empréstimo temporário do duplo do animal pelo duplo do xamã traz sempre consigo um grande risco: o de sofrer inesperadamente o ataque de algum caçador. Quando é esse o caso, não há destino outro, segundo Fischermann, que não a morte do xamã.

16 Constatação que constitui também uma das tônicas da descrição de Sebag (1965) sobre o xamanismo ayoreo.

17 Nesse sentido, imagino que se poderia sugerir ainda, a partir da tese de Fischermann, que menos que uma relação entre o duplo da pessoa humana e seus "espíritos auxiliares", o duplo do xamã ayoreo estabeleceria relações de troca simétrica de capacidades curativas com esses xamãs não-humanos. 
Possibilidade extra é ainda, segundo esse mesmo autor, a de que o próprio corpo do xamã sirva de veículo para o transporte até espaços como o sol. O autor destaca, ainda, que tal habilidade é privilégio apenas de poucos xamãs absolutamente poderosos. Sobretudo porque para o xamã convencional a capacidade xamânica puopié não é dotada de força suficiente para neutralizar a ação guerreira do sol, cujos raios figuram, sob a perspectiva do xamã, como flechas disparadas por ele.

Pois bem. Para o caso particular dos Ayoreo da região do alto Paraguay, penso que se pode afirmar que projeta-se sobre a ação xamânica a imagem do emprego individual de fórmulas sarode (sing. sari) ujnarone (sing. ujnari). São elas que qualificam a relação entre um regime discursivo e o pensamento sobre as relações entre um xamã, a pessoa enferma, o espaço onde ele é enunciado e diferentes formas de alteridade que passaram a povoar o cosmos Ayoreo após a cessão dos tempos míticos.

Sejam os sarode ou os ujnarone, eles possuem quase sempre uma estrutura fixa que põe repetidamente em paralelo a figura de um ser Jnanibajade ou Chequebajedie atualizado em modo não-mítico, e a expressão tu yure, 'eu mesmo.' Se há algo que varia caso a caso, este é o centro de agência que enuncia tu yure através das palavras de um xamã.

Eis abaixo, à guisa de exemplo e de caracterização do que mencionei acima, um sari. Um que traz à baila o tornado Acherangóri e é nomeado de Acherangóri sari. Através dele atualiza-se no plano da ação xamânica a figura do vento que, de tão forte, é dotado do poder de fazer dispersar as nuvens de chuva que formam-se sobre a aldeia. Conta-se, ademais, que Acherangóri, quando ainda atualizado em modo mítico/humano, era um grande matador, temível por todos e dono de um facão com a lâmina tingida permanentemente de vermelho e que hoje, pelo temor que acherangóri provocava, emprega-se este sari para 'amedrontar' (Ayoreo: -aguté) as enfermidades.

Pois vejamos melhor abaixo:

\section{Acherangori sari}

\section{Cuchai tu yure}

2. Cuchai tu yure, cuchape tu yure

3. Cuchape tu yure

\section{Acherangóri quicuijáide arojna tu yure}

5. Que pica site yijnose qjinére asi caratequejnati ta ye

6. Yugode cuchape ore guejnangori tu yure

7. Que pica site yoidi yijnosocoi asi carateguejnai ta ye

8. Yugode cuchape ore guejnangori tu yure

9. Acherangóri quicuijáide arojna tu yure

10. Cuchabi casi tu yure
1. Eu mesmo, poderoso

2. Eu mesmo, enorme e poderoso

3. Eu mesmo, enorme

4. Eu mesmo, a origem de Acherangóri

5. Ninguém ousa cruzar o caminho de meu facão, o poderoso vermelho

6. Eu mesmo, [aquele que] destrói os semelhantes, que são igualmente poderosos

7. Ninguém se atreve a aparecer diante de minha lança, a vermelha poderosa.

8. Eu mesmo, [aquele que] destrói os semelhantes, que são igualmente poderosos

9. Eu mesmo, a origem de Acherangóri

10. Eu mesmo, o poderoso que ninguém se atreve a desafiar. 
11. Je jme, je jme, je jme

12. Je ka, je ka, je ka

13. Je cüise, je cüise, je cüise

*sopro chubuchu*
11, 12 e 13. [ideófones dos sons dos galhos de árvores movidos pelo vento]

*sopro chubuchu*

Há de se perguntar: que são palavras-do-xamã (Ayoreo: naibae uruode)? São elas enunciação sua ou o xamã Ayoreo seria, de modo similar ao xamã Araweté (Viveiros de Castro 1986), um tipo de “rádio", através do qual ex-humanos enviam ao domínio habitado pelos humanos vivos suas mensagens?

Minha percepção acerca do emprego dos sarode e dos ujnarone na ação xamânica Ayoreo é de que as palavras-do-xamã são espécies de máquinas de produção de efeitos. Sua enunciação, ao referenciar-se aos seres originários já atualizados em modo não-mítico, acaba por se revelar um tipo de índice das relações entre a capacidade xamânica denominada pujopié, uma enfermidade, e um grupo de centros de agência que estabelecem entre si relações que outra ordem que as estabelecidas com o xamã ayoreo (Ayoreo: naihae).

Pretendo com isso sugerir que as palavras-do-xamã não tem nenhum tipo de suficiência em si, assim como tampouco seriam dotadas de significante. A ideia é que cada palavra que compõe um sari ou um ujnari é certamente um signo, mas um que não figura nunca desacoplado de um elemento extralinguístico e, acima de tudo, mítico (e, portanto, conservando também uma relação de vizinhança com a própria linguagem).

Enfim, se as fórmulas enunciadas pelo xamã à guisa de terapia para as enfermidades da pessoa humana ${ }^{18}$ são compostas por signos e elementos míticos que circulam por entre uma série temporal não-mítica/humana e outra mítica/ex-humana, componentes do cosmos Ayoreo desde o fim dos tempos míticos, não se pode dizer que a enunciação dos sarode ou dos ujnarone implique necessariamente na existência de um sujeito que preencha simultaneamente funções de universalização e de individuação.

O que está em questão aqui para o caso do xamanismo ayoreo, de acordo com meu parecer, é o fato de que tudo que parece se objetificar na forma de um sari ou de um ujnari são "agenciamentos" (Deleuze 2016: 209), no interior dos quais se abrigariam diferentes processos que cumprem a função de assinalar que formas de alteridade podem ocupar posições de sujeito ou na forma de imagens, ou na forma de signos. Assim e em suma, a voz do xamã feita audível na forma de sarode ou de um ujnarone, menos que uma voz humana, se faz a várias outras vozes não-humanas.

Sob esse enfoque, o que parece muito importante ainda é destacar e desenvolver algumas conexões que vislumbro entre esses agenciamentos e transformações e um modelo geral de relacionalidade que, no caso do xamanismo ayoreo, coloca em conexão três séries distintas e mutuamente implicadas: uma mítica, outra cósmica e outra política.

Tal constatação provém da sugestão dos Ayoreo de que a potência dos sarode e dos ujnarone e o perigo decorrente de sua enunciação encontram-se relacionados tanto a localidade onde determinada fórmula é enunciada, quanto a forma de alteridade a que se encontra vinculada.

18 Devo registrar que a condição de humano não é fator que limite a capacidade de intervenção deu xamã. Eu mesmo pude presenciar um caso de intervenção xamânica realizada numa vaca de um fazendeiro da região de Porto Murtinho, MS. 
Assim sendo, os sarode empregados, por exemplo, para o alívio de indigestão, dores de estômago ou de ouvido, para o tratamento de disenteria, para queimaduras provocadas pelo sol, para casos de entorse de algum membro, para o cansaço físico ou até mesmo para o crescimento dos cabelos são classificados pelos xamãs como sarode omome $e^{19}$, pois: (1) são fórmulas que não exigem muita precaução em seu emprego, dado que imperícia em seu uso não acarreta em nenhum dano maior; (2) não demandam que o xamã se distancie do espaço da aldeia para enuncia-las; (3) sua aplicação não requer que o xamã lance necessariamente mão do sopro chubuchu; (4) encontram-se vinculadas a formas de alteridade classificadas pelos Ayoreo como pouco perigosas e poderosas, como, por exemplo, a formiga cortadeira Najom, o porco do mato Ijancói, ou o beija-flor Saramia.

Os exemplos que tenho do emprego de sarode dessa categoria ocorreram quase todos no espaço do pátio doméstico da casa de um casal de xamãs na aldeia Tiogai e consistiram em agências sobre casos de febre leve, entorses, disenterias, infecções intestinais e inflamações de ouvido, tratados por eles com sarode omome e aplicação de massagens e sopros chubuchu nas áreas afetadas. Tudo realizado no próprio espaço de uma seção residencial que aglomera diariamente os parentes consanguíneos, afins e amigos formais ${ }^{20}$ (Ayoreo: acotéode) dos xamãs. E tanto quanto pude observar, a repetição desajeitada das palavras do xamã por parte de alguém, a troça feita através substituição de um animal por outro, ou a brincadeira das crianças, imitando uma com as outras o modelo de ação que observavam eventualmente, nunca pareceram nem condenáveis, nem recrimináveis. Ao contrário, pareciam ser motivo de grande entretenimento no espaço do pátio após a cessão do evento de cura xamânica

E eu pude observar em sessões de cura xamânica, cada caso era tratado com um grupo de sarode omome enunciados pelo xamã sequenciadamente. Para o caso, por exemplo, das infecções intestinais ou disenterias, um xamã deveria enunciar primeiramente (e repetidamente) o Najom ujnarone, para enunciar posteriormente o Ijnacói ujnarone. O essencial de fazê-lo nessa ordem remontava, segundo os xamãs, um esquema de parentesco mítico, que relacionava Najom a Ijancói atualizado no plano da ação xamânica, de modo que inverter a ordem de enunciação dos sarode omome, somado ao preterimento do sopro chubuchu e da prosódia e ortoépia, anula os efeitos que um grupo de fórmulas pode produzir.

No entanto, isso não é tudo sobre a agência xamânica Ayoreo. De outro modo, há também outra classe de fórmulas sarode que exige, alternativamente, absoluta perícia em seu emprego, demanda do xamã que ele se afaste do espaço da aldeia para pronunciá-los, e produz efeitos sobre o mundo físico apenas mediante o sopro chubuchu. São fórmulas chamadas de sarode datéode e encontram-se vinculadas a formas de alteridade reconhecidas quase sempre como uti. Que é a condição de uti? É aquela que diz respeito a reconfiguração corporal após o fim dos tempos míticos e a habitação de espaços destacados daquele convencionalmente habitado pelas pessoas de uma aldeia. São, portanto, centros de agência classificados de uti que atualizam sob a forma de terapia xamânica as capacidades que algumas formas de alteridade possuíam quando ainda não figuravam em modo não-mítico: a engole-vento

19 A mesma referência pode ser encontrada entre os Ayoreo bolivianos, segundo registro de Fischermann (2001), ainda que no contexto estudado por esse autor prolifere, alternativamente, a expressão sarode iyégode.

20 Para um desenvolvimento a respeito das relações de 'amizade formal', ver Fischermann (2001) e Grunewald (2015). 
Asojna; a morte (Ayoreo: toi); o coelho Guiorama; o iguana Poji; o jaburu Chunguperedatei; ou a urubu Jnanucutó.

De um modo geral, os sarode datéode correspondem a fórmulas cujo emprego é reservado apenas para situações graves e cuja aplicação encontra-se condicionada a faixa etária, condição corporal e a capacidade de um sujeito de mobilizar relações com outrem. Isso porque sua aplicação prática é restrita apenas dos casos de enfermidades sérias e não-curadas pelo emprego prévio de sarode omome, como, por exemplo, no caso do processo infeccioso ducosi, caracterizado pela irrupção de abcessos no corpo da pessoa enferma e de febre alta, quando se requer o emprego das fórmulas ducosi sari e yoté curesei.

Consequentemente, os xamãs ayoreo evitam a aplicação de sarode datéode em crianças enfermas ${ }^{21}$ por julgar que seus corpos não comportam o poder característico do ser Jnanibajade ou Chequebajedie associado àquela fórmula, reservando o emprego dessas fórmulas preferencialmente aos casos que acometem ou os grandes chefes (Ayoreo: dacasuté pise), cuja fama extrapola o grupo local, ou os Ayoreo velhos dito estarem 'cansados-de-viver' (Ayoreo: choquijnajnupi). Estes, particularmente, por serem reputados serem donos de corpos fragilizados e quase destituídos do princípio vital ayipié, nos quais os riscos impostos pelo emprego de sarode datéode estariam minimizados. Aqueles, por serem dotados de corpos fortificados pelas relações que acumulam com as pessoas pertencentes a diferentes grupos locais.

Agora, desde que cheguei entre os Ayoreo na região do alto Paraguay e durante boa parte do tempo que estive com eles, esses enunciados acerca da aplicação dos sarode datéode pareciam integrar um grupo composto por outros, através dos quais se enfatizava que as fórmulas só podem ser enunciadas no espaço externo ao círculo de parentes consanguíneos e afins reais do xamã que compõem seu grupo doméstico (Ayoreo: jogasui). Nesses casos a distância que separa um pátio doméstico de outro vizinho (que, teoricamente, não abriga obrigatoriamente nas aldeias ayoreo do alto Paraguay nem os consanguíneos nem os afins reais e imediatos do xamã) já seria suficiente para que um xamã pudesse enunciar uma fórmula específica considerada 'interditada' (Ayoreo: puyák $k^{22}$ ) em seu próprio grupo doméstico.

E de onde provém a interdição? A palavra dos xamãs ayoreo é que esta origina-se, sobretudo, na imprevisibilidade dos efeitos que sua enunciação, somada ao sopro chubuchu, poderia provocar num espaço doméstica tipicamente marcado pela 'estabilidade' característica das relações entre parentes e permissivo somente com a enunciação de sarode omome.

Portanto, qualquer espaço exterior ao círculo definido pelos parentes num jogasui seria propício, por exemplo, para a enunciação de um sari datéode? Não tão rápido. Direi que são os espaços domi-

21 Há casos, porém, de enfermidades absolutamente graves que são passíveis de serem tratadas com sarode datéode. Imagino que pela percepção das pessoas desse povo que os efeitos danosos provocados pela ação xamânica são menos nocivos que a doença em si.

22 Especificamente sobre o conceito Ayoreo de Puyák, ver o trabalho de Otaegui (2011). 
nantemente marcados pela afinidade potencial ${ }^{23}$ (cf. Viveiros de Castro 2002), como as localidades de Porto Murtinho, Assunção, Campo Grande e Carmelo Peraltaa ${ }^{24}$, são especialmente destinados à enunciação de fórmulas datéode. Particularmente aquela que as pessoas de Tiogai conhecem como Poji sari (ou como Poji ujnari), que presentifica na forma de ação xamânica o evento do ressuscitamento frustrado do iguana Poji e é enunciada em contextos caracterizados pela presença massiva de Brancos - como, por exemplo, a praça da cidade de Porto Murtinho - a fim de obter deles objetos conceitualizados, sob sua perspectiva, como absolutamente poderosos e como decididamente perigosos.

Contudo, a impressão que tive entre os Ayoreo é que tudo se passa como se houvesse entre os Brancos (Ayoreo: cojñone) afins 'mais potenciais' que outros.

Dentre os que habitam as imediações das aldeias, há aqueles que eventualmente podem vir a se transformar em afins reais das pessoas de um ou outro grupo doméstico. Assim como há também aqueles que, mesmo à distância, podem conservar a potência específica (bem como a latência) de sua posição de afim, figurando aos olhos das pessoas desse povo como seres agutiyamáinióde: 'apoiadores', a quem as pessoas de uma aldeia podem recorrer quando necessitam eventualmente de algum auxílio, como um determinado objeto, uma passagem de ônibus para Assunção, crédito para um telefone celular, ou um pouco de dinheiro para alguma viagem. Em troca, aqueles que ocupam essa posição (e diferentemente de outros que também figuram como afins potenciais, mas que não ocupam a posição de agutiyamáinióde) encontram-se habilitados, conforme afirmei alhures (Grünewald 2015), a aprender a xamanizar através do emprego tanto de sarode omome quanto de sarode datéode considerados menos nocivos e agressivos.

Mas há o outro lado. O dos sarode datéode classificados como mais agressivos e distintamente danosos, como, por exemplo, Guiorama sari, ou os sarode que atualizam na forma de agência xamânica os eventos míticos referenciados a engole-vento Asojna. Hipoteticamente, estes só podem ser enunciados em espaços que figuram no pensamento Ayoreo como localizados em pontos de distância máxima das aldeias, como, por exemplo, o Japão ou a Itália ${ }^{25}$. Terrenos de onde vinham também, segundo o julgamento dos Ayoreo, boa parte daqueles que iam a Tiogai aprender o que quer que seja sobre sarode e ujnarone. Esses espaços caracterizados como não-puyák e como suficientemente distantes para que os efeitos dos sarode e dos ujnarone mais nocivos não se dispersem sobre as pessoas do grupo doméstico do xamã, são, portanto, lugares privilegiados para a atualização de seres Jnanibajade e Chequebajedie através das palavras do xamã e por meio da estrutura dos sarode e dos ujnarone.

\footnotetext{
23 Segundo Viveiros de Castro (2002), nos sistemas sul-americanos a oposição entre consanguinidade e afinidade é menos diametral que concêntrica, numa dimensão ideológica e eventualmente noutra do emprego terminológico. De modo que nesses sistemas "os consanguíneos estão no centro do campo social, os afins na periferia, os inimigos no exterior. Ou melhor, no centro deste campo estão os consanguíneos e os afins cognáticos co-residentes, todos concebidos sob o signo comportamental da consanguinidade, que no nível local engloba a afinidade; na periferia do campo estão os consanguíneos distantes e os afins potenciais-classificatórios, dominados pelo signo da afinidade potencial, que ali engloba a consanguinidade; no exterior estão os inimigos, categoria que pode receber e fornecer afins potenciais, assim como o segundo círculo recebe consanguíneos distantes e devolve eventualmente afins reais. Concêntrico, o sistema é também dinâmico". (Viveiros de Castro 2002: 136)
}

24 Tipicamente marcados, note-se, pela presença intensiva de Brancos (Ayoreo: cojñone).

25 Penso que a referência em 2012 e 2013 ao Japão e a Itália deva-se ao fato de que, segundo os Ayoreo, pouco antes de minha chegada um antropólogo italiano passou algum tempo com os Ayoreo na aldeia Tiogai e uma expedição japonesa esteve nessa mesma localidade a fim de registrar o emprego das fórmulas sarode e ujnarone. 
E assim podemos entender que a ação xamânica assume nesse quadro o aspecto de um objeto folheado, no âmbito do qual a intensidade dos sarode omome e datéode se justapõe a um gradiente ontológico e a outro espacial, que é cortado transversalmente por uma certa coloratura (na acepção musical do termo) da afinidade potencial: são aqueles que vem do exterior de um grupo doméstico - terreno tipicamente povoado por não-humanos como animais, espíritos, Brancos e inimigos -, os que teoricamente se interessam pelos sarode mais potentes. E é o espaço de proveniência desses centros de agência concebido como o mais apropriado para a enunciação dos sarode datéode mais potentes e nocivos.

Isso lança luz sobre a ideia de que o "wider whole" (para empregar aqui a grata expressão de Overing (1984: 148)) da sociedade ayoreo, esse todo mais amplo que se produz no avesso de um espaço dominado pelos parentes aglomeradas num mesmo grupo doméstico, é o espaço de onde provém os seres não-humanos - cuja potência é atualizada através dos sarode e dos ujnarone. Simultaneamente, esse mesmo terreno é concebido como a origem daqueles que se interessam pelos sarode e ujnarone restritos de serem empregados no espaço dominado pela estabilidade e pela minimização da potência agressiva típica dos domínios marcados pela não-humanidade dos seres que os povoam, por trocas simétricas e pela replicação das relações de aliança.

Como última observação sobre esse ponto, devemos notar ainda que se é dessa imagem da sociedade Ayoreo, repleta de afins potenciais e de não-humanos poderosos e agressivos atualizados em modo não-mítico, de onde provém a potência cósmica da ação xamânica, parece ser igualmente para esse wider whole que o xamã, juntamente com a pessoa enferma, se abre por ocasião de um evento de cura xamânica. Para um conjunto, então, de relações unidirecionais e complementares que propiciam a despotencialização de uma constante agressiva e predatória e sua conversão em aliança simétrica.

\section{Conclusão}

É chegado o momento de concluir. Ao longo das páginas desse artigo, observamos como um conjunto de acontecimentos teria tido implicações na constituição de mundos e de modos de existência irredutíveis uns aos outros, mas comunicáveis entre si, juntamente com as conexões entre esses eventos com a imagem de um modelo de ação xamânica. Assim como vimos também que nos eventos míticos de atualização de formas de alteridade em modo não-humano, a humanidade mítica não prefigurava enquanto modelo para a ex-humanidade não-mítica de outrem. A aposta era a de que se tratava ali, distintamente, de processos de reconfiguração ontológica que modificavam a modo de existência de um determinado sujeito, fazendo com que a animalidade passasse a operar, após a cessão dos tempos míticos, como um efeito da composição de uma nova estrutura e de um novo modo de existência.

Também esteve diante de nós a constatação de que as palavras do xamã ayoreo enunciadas na forma de sarode ou de ujnarone não tem nem significante, nem suficiência em si. Ao contrário, elas são signos que figuram acoplados a um elemento mítico e circulam conjuntamente por uma série temporal não-mítica/humana e outra mítica/ex-humana. Donde pudemos sugerir igualmente que as fórmulas empregadas pelo xamã ayoreo abrigam diferentes processos que cumprem a função de assinalar que formas de alteridade podem ocupar posições de sujeito, ou na forma de imagens, ou na forma de signos. 
E diante dessa proposição, pudemos observar igualmente que esses agenciamentos se conectavam a um modelo de relacionalidade que, no caso do xamanismo, conectava o emprego de uma classe de fórmulas xamânica a outras séries distintas, mas mutualmente implicadas.

Mas apesar das várias camadas desse texto e dos múltiplos temas que se conectam a elas, gostaria mesmo de apontar, à guisa de conclusão, que as relações entre o modo de ação de um xamã e as formas míticas atualizadas em modo não-humanas dão vistas a "heteronomia ontológica" (Sterpin 1993) da sociocosmologia ayoreo. Esta figura em que a posição de Outro não-humano aparece como condição para a possibilidade de ação xamânica. O que o xamã atualiza através de suas palavras? Menos que uma metáfora das capacidades de sujeitos míticos ex-humanos, a incorporação da posição que essas formas de alteridade ocupam à sua própria perspectiva.

O xamã é aquele que é humano, o humano foi vento e foi tabaco, que perderam, por seu lado, a condição de humano após o fim dos tempos míticos, mas que se atualizam enquanto humanos e enquanto xamãs nas formas sarode e ujnaron. $\mathrm{O}$ que se encontra verdadeiramente em jogo neste caso são "torções topológicas de virar-outro" (Viveiros de Castro idem: 254) num modo de ação em que as formas de alteridade trazidas à baila nas palavras do xamã operam como qualificativos que se relacionam menos com uma ideia de sujeito que com a imagem de um ato. $\mathrm{O}$ xamã ayoreo é então aquele que a absorve e atualiza na linguagem a posição do animal, que é aquela de ex-humano, revelando uma metafísica em que o animal ex-humano é o personagem central e a afinidade figura como um elemento essencial.

\section{Leif Ericksson Nunes Grünewald é doutor em Antropologia pela Universidade Federal Fluminense (UFF) e bolsista PNPD do Programa de Pós-Graduação em Antropologia da Universidade Federal da Grande Dourados (UFGD).}

\section{REFERÊNCIAS BIBLIOGRÁFICAS}

ARENAS, Pastor. 1981. Etnobotánica Lengua-Maskoy. Buenos Aires: Fundación para la Educación, la Ciencia, y la Cultura.

BREMEN, Volker Von. 1991. Zwischen Anpassung und Aneignung: Zur Problematik von Wildbeuter-Gesellschaften im modernen Weltsystem am Beispiel der Ayoréode. München: Anacon-Verl.

CLASTRES, Pierre. 1967. “De Quoi Rient Les Indiens?” Les Temps Modernes n. 253. pp. 2179 2198

DELEUZE, Gilles. 2016. Critica e Clínica. Rio de Janeiro: Editora 34.

GRUNEWALD, Leif. 2015. O Fascismo dos Homens Bons: Sobre padres e os Ayoréode do Alto Paraguay. Tese de Doutorado. Niterói: Universidade Federal Fluminense 
KELM, Heinz 1971 “Das Jahrefest der Ayoreo Indianer”, Baessler-Archiv, Neue Folge, Band XIX, pp. 97-140.

LÉVI-STRAUSS, Claude. 1985. La potière jalouse. Paris: Plon. 2004. O Cru e o Cozido: Mitológicas I. São Paulo: Cosac Naify.

LIMA, Tania Stolze. 1996. "O dois e seu múltiplo: reflexões sobre o perspectivismo em uma cosmologia tupi". Mana. 1996, vol.2, n.2, pp.21-47

MÉTRAUX, Alfred. 1946. "Ethnography of the Chaco”. In. Steward, Julian H. (ed.) Handbook of South American Indians Vol. 1: The marginal tribes, p. 197-370 Smithsonian Institution, Bureau of American Ethnology, Bulletin 143 Washington: Government Publishing Office. 1967. Religions et magies indiennes d'Amérique du Sud. Paris: Gallimard.

OTAEGUI, Alfonso. 2011. "Os Ayoreo aterrorizados: Uma revisão do conceito de puyák em Bórmida e uma releitura do Sebag”. Runa. 2011, vol.32, n.1, pp. 9-24.

2014. Les Chants De Nostalgie Et De Tristesse Des Ayoreo Du Chaco Boréal Paraguayen (Une Ethnographie Des Liens Coupés). Tese de Doutorado. Paris: EHESS.

OVERING, Joanna. 1984. "Dualism as an expression of difference and danger: marriage exchange and reciprocity among the Piaroa of Venezuela", in: K. Kensinger (org.). Marriage Practices in Lowland South American Societies. Urbana: Univ. of Illinois Press, pp. 127-155.

SEBAG, Lucien, 1965. "Le chamanisme ayoréo", L’Homme v.1, janeiro-março: 7-32; v.2, abril-junho: 92-122.

. 1977: Les Ayoré du Chaco septentrional. Étude critique à partir des notes de Lucien Sebag. La Haya: Mouton.

STERPIN, Adriana. 1993. "La chasse aux scalps chez les Nivacle du Gran Chaco". Journal de la Sociétédes Américanistes, V. 79, N.1 p. 33 - 66

SZTUTMAN, Renato. 2005. O profeta e o principal. A ação politica amerindia e seus personagens. Tese de Doutorado (Antropologia Social). Universidade de São Paulo.

2006. Cartografias xamânicas nas Guianas. Texto apresentado no colóquio "Guiana Ameríndia”. Belém, NHII-USP/EREA-CNRS/MPEG.

TOLA, Florencia. 2004. Je ne suis pas seul(ment) dans mon corps. Corps et multiplicités chez les Toba (Qom) du Gran Chaco. Tese de Doutorado. Paris. EHESS.

.2011. "Chamanisme et sorcellerie chez les Toba (Qom) du Gran Chaco sud-américain. Quelques remarques sur une conception non-individuelle du corps". In: Klein, Alexandre e Dagognet, François. Les sensations de santé - Pour une épistémologie des pratiques corporelles du sujet de 
santé. Lorraine: Presses universitaires de Nancy - Éditions universitaires de Lorraine. pp. 23-40.

VILLAGRA, Rodrigo. 2010. The two shamans and the owner of the cattle: alterity, storytelling and shamanism amongst the Angaité of the Paraguayan Chaco. Tese de Doutorado. Saint Andrews. University of Saint Andrews.

VIVEIROS DE CASTRO. 1986. Araweté: Os Deuses Canibais. Rio de Janeiro : Jorge Zahar.

. 1996. “Os pronomes cosmológicos e o perspectivismo ameríndio". Mana 2. Rio de Janeiro: Museu Nacional, Contra Capa . pp. 115-144.

.2002. Atualização e contraefetuação do virtual: o processo do parentesco. In: Viveiros

de Castro, Eduardo: A inconstância da alma selvagem e outros ensaios de Antropologia. São Paulo:

Cosac \& Naify, 401-456. 


\section{UMA SOCIOCOSMOLOGIA E SEUS COMPONENTES: DE UM MODELO MÍTICO ÀS OPERAÇÕES XAMÂNICAS AYOREO}

Resumo: Neste artigo, busca-se conectar um conjunto de relatos sobre eventos míticos de constituição de mundos heterogêneos entre si à descrição sobre o xamanismo Ayoreo, um grupo Chaquenho falante de uma língua Zamuco que habita tradicionalmente a região do Chaco Boreal mas distribui-se até a região do alto Paraguay. Com esse propósito, e através da exposição das conexões entre os tempos míticos e as operações xamânicas dos tempos atuais, deseja-se analisar especialmente o modo como ambos se articulam na definição das categorias ontológicas que constam na sociocosmologia Ayoreo e suas espécies distintas de habitantes que a compõem.

Palavras-Chave: Mitologia; Ayoreo; Chaco; Xamanismo

\section{A SOCIOCOSMOLOGY AND ITS COMPONENTS: FROM A MYTHICAL MODEL TO SHAMANIC OPERATIONS AYOREO}

Abstract: This article aims to connect mythical accounts of the composition of heterogeneous worlds to a picture of Ayoreo shamanism, a Zamucoan-speaking group who lives in Paraguayan Chaco Boreal, but can be found also in the region of border between Brazil and Paraguay. To this end, and through the connections between mythical times and contemporary shamanism, we aim to analyze how they relate to the definition of ontological categories of Ayoreo sociocosmology and the different species that compose it.

Keywords: Mythology; Ayoreo; Chaco; Shamanism

RECEBIDO EM: 31/01/2017

APROVADO EM: 18/08/2017 
